\title{
Sorafenib modulates the radio sensitivity of hepatocellular carcinoma cells in vitro in a schedule-dependent manner
}

\author{
Qiaoqiao Li ${ }^{1,2 \dagger}$, Yonghong Hu ${ }^{1,2 \dagger}$, Mian Xi ${ }^{1,2}$, Liru He ${ }^{1,2}$, Lei Zhao ${ }^{1,2}$ and Mengzhong Liü ${ }^{1,2^{*}}$
}

\begin{abstract}
Background: Hepatocellular carcinoma (HCC) has a high incidence and mortality. Radiotherapy and sorafenib have proven effective for HCC. Here, we investigated whether sorafenib modulated the response of HCC cells to irradiation in vitro, effect of timing of sorafenib, and the underlying mechanisms.

Methods: Cell viability of the HCC cell lines, SMMC-7721 and Bel-7402, was examined by the 3-(4,5-dimethylthiazol2-yl)-5(3-carboxymethoxyphenyl)-2(4-sulfophenyl)-2 H-terazolium (MTT) assays. Clonogenic growth assays of SMMC-7721 and Bel-7402 were determined by colony formation assays. DNA damage was assessed by monitoring $Y$-HAX foci in irradiated cells with immunofluorescence microscopy, and cell cycle distribution changes were examined by flow cytometry. Effects of sorafenib $(15 \mu \mathrm{M})$ added 30 min prior to radiation (pre-irradiation sorafenib) of SMMC-7721 and BEL-7402 or 24 h post-irradiation (post-irradiation sorafenib) on irradiated SMMC-7721 and BEL-7402 cells were compared to those of radiation alone or no treatment.

Results: The effect of sorafenib was dependent on its time of addition in relationship to irradiation of cells. Pre-irradiation sorafenib did not significantly affect the viability of SMMC-7221 and BEL-7402 cells compared with irradiation treatment alone. In contrast, post-irradiation sorafenib increased the sensitivity of irradiated SMMC-7221 and BEL-7402 cells significantly in a time-dependent manner. Pre-irradiation sorafenib significantly increased the surviving fraction of SMMC-7221 and BEL-7402 cells in clonogenic assays whereas post-irradiation sorafenib significantly reduced the surviving fractions of SMMC-7221 and BEL-7402 cells. SMMC-7721 cells treated with sorafenib 30 min before irradiation had significantly fewer cells with $\gamma$-H2AX foci $(23.8 \pm 2.9 \%)$ than SMMC-7721 cells receiving radiation alone $(59.9 \pm 2.4 ; P<0.001)$. Similarly, BEL-7402 cells receiving sorafenib prior to irradiation had significantly fewer cells with $\gamma$-H2AX foci $(46.4 \pm 3.8 \%)$ than those receiving radiation alone $(25.0 \pm 3.0 \%$; $P<0.001)$. In addition, irradiation (6 Gy) caused a significant increase in the percentage of both SMMC-7721 and BEL-7402 cells in G2/M at 12 to $16 \mathrm{~h}$ post irradiation, which was markedly delayed by pre-irradiation sorafenib.
\end{abstract}

Conclusions: Sorafenib combined with irradiation exerted a schedule-dependent effect in HCC cells in vitro, which has significant implications for the combined use of sorafenib and radiotherapy for HCC patients.

Keywords: Hepatocellular carcinoma, Radiation, Sorafenib, Apoptosis, DNA damage repair

\footnotetext{
* Correspondence: liumengzhong@126.com.cn

${ }^{\dagger}$ Equal contributors

${ }^{1}$ Department of Radiation Oncology, SunYat-sen University Cancer Center

Guangzhou, 651 Dongfeng Road East, Guangzhou 510060, China

${ }^{2}$ State Key Laboratory of Oncology in South China, Guangzhou, China
} 


\section{Background}

Primary hepatocellular carcinoma is the $6^{\text {th }}$ most common malignancy in the world and ranks $3^{\text {rd }}$ among causes of cancer-related death. Hepatocellular carcinoma is prevalent in China and accounts for $55 \%$ of all hepatocellular carcinoma cases in the world [1]. Despite the best therapeutic regimen currently available, hepatocellular carcinoma has a dismal outcome with the five-year survival rate of $3 \%-10 \%$ for metastasized HCC and $28 \%$ for locally confined HCC. Approximately $80 \%$ of hepatocellular carcinoma patients have inoperable cancer at the time of diagnosis [2]. The median survival for patients with inoperable hepatocellular carcinoma is generally about 6 months [2].

Recently, adjuvant radiotherapy has shown promise as a treatment for inoperable hepatocellular carcinoma with a response rate of $30 \sim 67 \%$ [3-5]. Since radiotherapy is limited by poor tolerance of radiation in adjacent normal tissues, and regional radiotherapy has no tangible effect on intrahepatic and distant metastasis, agents that boost the sensitivity to radiotherapy are sought. Sorafenib is a multikinase inhibitor with anti-proliferative and antiangiogenic effects. It inhibits the activity of the serine/ threonine kinases c-Raf and B-Raf; the mitogenactivated protein kinases MEK and ERK; vascular endothelial growth factor receptors (VEGF); platelet-derived growth factor receptors (PDGFR); the cytokine receptor c-KIT; the receptor tyrosine kinases Flt-3 and RET; and the Janus kinase/signal transducer and activator of transcription (JAK/STAT) pathway [6]. Phase III clinical studies have shown that sorafenib is efficacious in patients with advanced hepatocellular carcinoma $[7,8]$, and sorafenib is the most recent drug approved for hepatocellular carcinoma. However, sorafenib only modestly improves the outcome of hepatocellular carcinoma patients, prolonging the median survival of patients with inoperable hepatocellular carcinoma by less than 3 months [7]. Mechanistically, sorafenib increases apoptosis of the hepatocellular carcinoma cells, PLC/PRF/5 and HepG2 cells [9] as well as some breast cancers, colorectal carcinomas, osteosarcomas, and glioblastomasbut not all types of tumor cells [10]. Sorafenib may augment radiotherapy of $\mathrm{HCC}$ because administration of sorafenib post-irradiation markedly potentiated the inhibitory effect of irradiation on growth of mouse colorectal cancer xenografts compared to irradiation alone [10]. However, the combination of irradiation and concurrent sorafenib administration had no significant effect on tumor growth [10]. Suen et al. [11] investigated the combined effect of sorafenib and irradiation on colorectal cancer cells: only sorafenib given post irradiation augments the inhibitory effects of irradiation on clonogenic growth. Interestingly, three renal cell carcinoma patients who relapsed under sorafenib were subsequently co-administered radiotherapy [12]. Sorafenib treatment was administered both prior to and concurrently with radiation [12]. In these three RCC cases, the tumor mass shrunk, pain diminished or was abolished, and patients reported no late side effects [12].

We hypothesized that sorafenib may also boost the efficacy of irradiation on HCC in a schedule-dependent manner. A case report of a patient with inoperable HCC who was initially treated with sorafenib provides support of interaction between radiotherapy and sorafenib during treatment of HCC [13]. The patient's history included sorafenib treatment, its subsequent discontinuation due to side effects, unchecked tumor growth, treatment with both radiotherapy and sorafenib, tumor shrinkage, and the recurrence of sorafenib-related rash [13]. Currently, optimization of combined irradiation and sorafenib in hepatocellular carcinoma has not been described, and the mechanisms of irradiation enhanced by sorafenib are still ambiguous. We investigated the effect of combined radiotherapy and sorafenib on two hepatocellular carcinoma cell lines, SMMC-7721 and BEL-7402, and the underlying mechanisms of interaction.

\section{Methods}

\section{Cell lines and agents}

Human hepatocellular carcinoma cell lines, SMMC-7721 and Bel-7402, were obtained from Nanfang Hospital of Southern Medical University, Guangzhou, Guangdong, China [14], and were cultured in RPMI-1640 supplemented with $10 \%$ heat-inactivated fetal bovine serum (FBS) (Hyclone, Logan City, Utah) at $37^{\circ} \mathrm{C}$ in a humidified atmosphere containing $5 \% \mathrm{CO}_{2}$. Sorafenib (Bayer, Leverkusen, Germany) was dissolved in dimethyl sulfoxide (DMSO) to a stock concentration of $25 \mathrm{mmol} / \mathrm{L}$ and stored at $-20^{\circ} \mathrm{C}$.

\section{The 3-(4,5-dimethylthiazol-2-yl)-5(3-} carboxymethoxyphenyl)-2(4-sulfophenyl)-2 H-terazolium (MTT) assays

The MTT (3-(4,5-dimethylthiazol-2-yl)-5(3-carboxymethoxyphenyl)-2(4-sulfophenyl)-2 H-terazolium) assays (Promega, Madison, WI) were performed as instructed by the manufacturer to assess cell viability. Briefly, SMMC-7721 ( $3 \times 1^{3}$ cells/well) and BEL-7402 cells $\left(4 \times 10^{3}\right)$ were seeded into 96 -well plates in quadruplicate. After incubation for $1 \mathrm{~d}$, cells were treated with sorafenib $30 \mathrm{~min}$ before (pre-irradiation sorafenib) or $24 \mathrm{~h}$ following irradiation (post-irradiation sorafenib). Cells were irradiated at the indicated doses using a ${ }^{60} \mathrm{Co}$ irradiator. Cell viability was measured on $\mathrm{d} 0$ to $\mathrm{d} 6$ after irradiation. Absorbance values were shown as the percentage of the treated samples relative to the controls which received neither irradiation nor sorafenib. Inhibition of cell growth was measured as the percentage of 
viable cells relative to the controls, which was calculated as follows: $\%$ of viable cells $=\mathrm{OD}_{\mathrm{T}} / \mathrm{OD}_{\mathrm{C}} \times 100 \%$, where $\mathrm{OD}_{\mathrm{T}}$ is the average OD value of the treatment samples, and $\mathrm{OD}_{\mathrm{C}}$ is the average $\mathrm{OD}$ value of the control samples. Results were analyzed using the CalcuSyn software program (Biosoft, Cambridge, UK). Combination indices (CI) were used to assess the interaction between the two treatment modalities.

\section{Apoptotic study and cell cycle analysis}

SMMC-7721 and BEL-7402 cells were irradiated, treated with sorafenib for 30 min followed by irradiation (pre-irradiation sorafenib), or irradiated and treated $24 \mathrm{~h}$ later with sorafenib (post-irradiation sorafenib). Apoptosis was detected in cells washed with phosphate buffered saline (PBS) at $48 \mathrm{~h}$ post-irradiation (irradiated controls, pre-irradiation sorafenib) or $72 \mathrm{~h}$ post-irradiation (postirradiation sorafenib) by staining with annexin $\mathrm{V}$ and propidium iodide as instructed by the manufacturer (BD Biosciences, Franklin Lake, NJ). Stained cells were analyzed by flow cytometry with a FACSCalibur flow cytometer (BD Biosciences). For cell cycle analysis, treated cells were washed once with PBS, trypsinized, washed in PBS with 2\% FBS, fixed in ice-cold ethanol for at least $1 \mathrm{~h}$, washed, stained with propidium iodide $(30 \mu \mathrm{g} / \mathrm{mL})$, and treated with RNase $(0.6 \mathrm{mg} / \mathrm{ml})$ in PBS plus $0.5 \%$ (v/v) Tween 20 and 2\% FBS. Stained cells were analyzed on a FACSCalibur flow cytometer (BD Biosciences) by using the CellQuest software. Mod-Fit program (Verity Software House Inc., Topsham, ME) was used to analyze the cell-cycle profiles.

\section{Colony formation assays}

This procedure was performed as previously described [15]. Briefly, cells were irradiated at a dose of $0,2,4$, and 8 Gy alone or in combination with sorafenib administered 30 min prior to (pre-irradiation sorafenib) or $24 \mathrm{~h}$ following irradiation (post-irradiation sorafenib). After incubation of $12 \mathrm{~d}$ (SMMC-7721) or 14 d (BEL-7402), cells were stained with $0.5 \%$ crystal violet in absolute ethanol, and colonies containing more than 50 cells were counted under a dissection microscope. Clonogenic survival curves were constructed by fitting the average survival levels. Subsequent experiments utilized a radiation dose of 6 Gy because the percentage of cells remaining after 8 Gy (SMMC-7721: 0.9-4\%; BEL-7402: $2-5 \%$ ) was too low for analysis. SMMC-7721 and BEL7402 cells in subsequent experiments received one of the four treatments: (a) none (control), (b) 6 Gy radiation, (c) $15 \mu \mathrm{M}$ sorafenib $30 \mathrm{~min}$ before 6 Gy radiation, or (d) 6 Gy radiation followed 24 h later with $15 \mu \mathrm{M}$ sorafenib.

\section{DNA damage immunofluorescence microscopy}

Immunofluorescence microscopy was done as previously described [16]. Rabbit anti- $\gamma-\mathrm{H} 2 \mathrm{AX}$ antibody (serine 139; Abcam, Cambridge, MA), and secondary antibodies Alex Fluor 488 goat anti-rabbit IgG (Invitrogen, Carlsbad, CA) were used. Nuclear staining was done by using 4, 6-diamidino-2-phenylindole (DAPI) (Vector Laboratories, USA). A cell containing more than $10 \gamma$-H2AX foci was considered to be positive for damages to DNA.

\section{Cell cycle G2/M distribution assay}

After the indicated time period, cells were rinsed with PBS, fixed with $70 \%$ ethanol, and incubated overnight at $-20^{\circ} \mathrm{C}$. Fixed cells were washed and suspended in $500 \mu \mathrm{l}$ of staining solution $(50 \mathrm{mcg} / \mathrm{ml}$ of propidium iodide, $100 \mathrm{mcg} / \mathrm{ml}$ RNAase and $0.2 \%$ Triton X-100) for $30 \mathrm{~min}$. The fluorescence associated with PI-bound DNA was measured by flow cytometry (Beckman Coulter, cytomics FC 500, CA). Cell cycle profiles of G2/M phase were calculated using MultiCycle software.

\section{Cell proliferation assays}

SMMC-7721 and BEL-7402 cells were plated at $1 \times 10^{3}$ cells per well in collagen-coated 96-well plates. Cell proliferation assays were performed by using the Cell Counting Kit-8 (CCK8) (Dojindo, Kumamoto, Japan) according to the manufacturer's protocol. Briefly, a $10 \mu \mathrm{L}$ of CCK-8 solution was added to each well and incubated at $37^{\circ} \mathrm{C}$ for $2 \mathrm{~h}$ in a humidified $\mathrm{CO}_{2}$ incubator. Optical density (OD) was measured at $450 \mathrm{~nm}$ using a Microplate Reader (Bio-Tek Instruments, Winooski, VT) and the proliferation index was calculated as the experimental OD value/control OD value. Each experiment was done in quadruplicate and at least three times independently.

\section{Apoptosis assays}

After incubation for $0 \mathrm{~h}, 24 \mathrm{~h}$, or $48 \mathrm{~h}$ after sorafenib treatment, cells were harvested, rinsed, and stained with Annexin V-FITC and propidium iodide, as previously described [17].

\section{Statistical analyses}

Normally distributed continuous variables were compared by one-way analysis of variance (ANOVA). When a significant difference between groups was apparent, multiple comparisons of means were performed using the Dunnett test. Data are presented as mean \pm standard deviation (SD). All statistical assessments were twosided and evaluated at the 0.05 level of significant difference. Statistical analyses were performed using SPSS 15.0 statistics software (SPSS Inc, Chicago, IL). 


\section{Results}

Sorafenib modulated radio sensitivity of hepatocellular carcinoma cells in a schedule-dependent manner

To investigate whether sorafenib modulated the response of hepatocellular carcinoma cells to radiation, we added sorafenib $30 \mathrm{~min}$ prior to or $24 \mathrm{~h}$ following irradiation of hepatocellular carcinoma cells SMMC-7721 and BEL-7402 and measured cellular viability by MTT for 6 days (Figure 1). Pre-irradiation sorafenib did not significantly affect the viability of SMMC-7221 and BEL7402 cells (Figure 1A and 1B) $(P>0.05)$. In contrast, post-irradiation sorafenib reduced the sensitivity of irradiated SMMC-7221 and BEL-7402 cells significantly in a time-dependent manner (Figure $1 \mathrm{~A}$ and $1 \mathrm{~B})(P<0.05)$. These findings suggested that sorafenib modulated the radio sensitivity of hepatocellular carcinoma cells in a schedule-dependent manner in vitro.

To further assess the effect of sorafenib on the radio sensitivity of HCC cell lines, we performed clonogenic assays. Radiation caused a dose-dependent cytotoxic effect on SMMC-7221 and BEL-7402 cells with less than $20 \%$ of cells surviving at 4 Gy and less than $0.1 \%$ of cells surviving at $10 \mathrm{~Gy}$. The surviving fraction of SMMC7221 and BEL-7402 cells was $0.15 \pm 0.05$ and $0.24 \pm 0.02$, respectively, at an irradiation dose of 4 Gy. Preirradiation sorafenib significantly increased the surviving

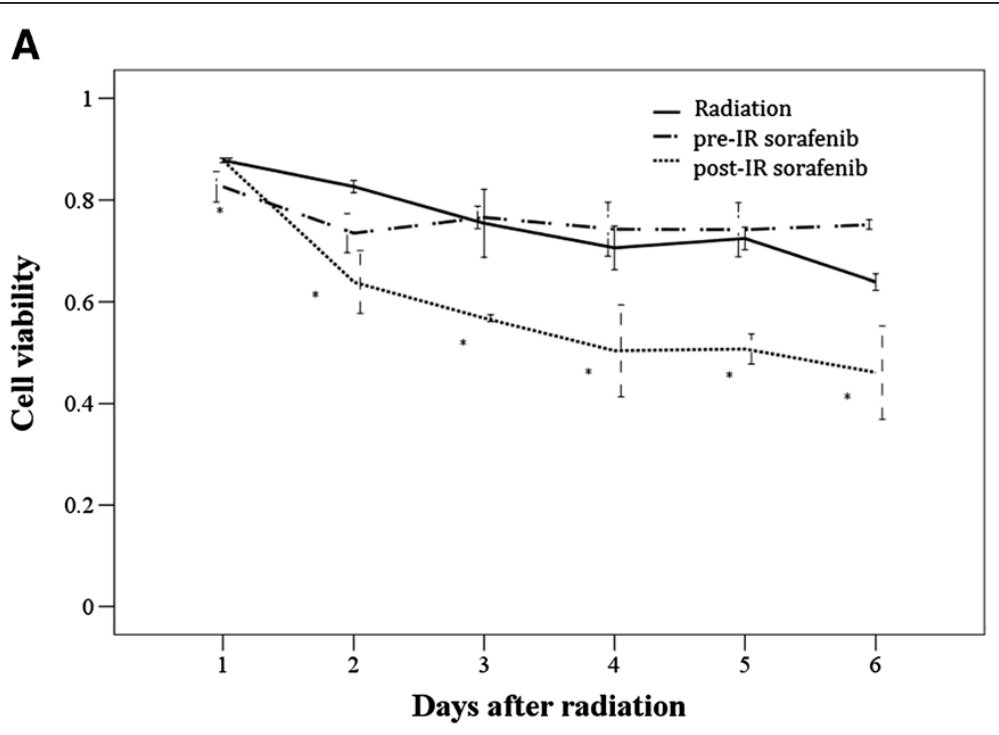

B

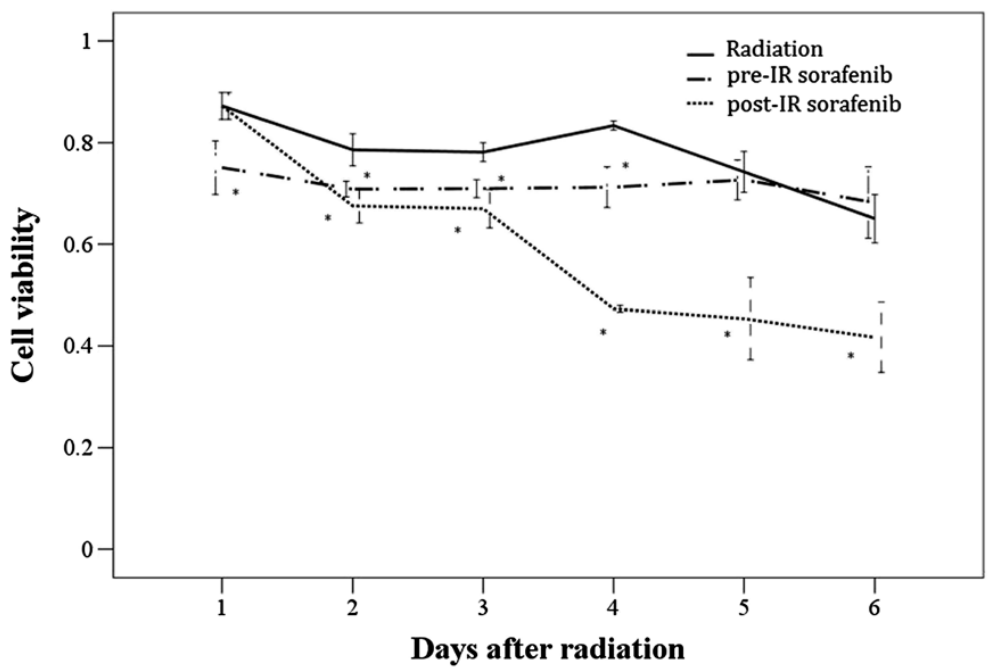

Figure 1 Effect of sorafenib treatment on cell viability of irradiated SMMC-7721 (A) and BEL-7402 cells (B). Cells were treated with radiation, sorafenib 30 min prior to irradiation (pre-IR sorafenib), or $24 \mathrm{~h}$ post irradiation (post-IR sorafenib), and MTT assays were performed to measure the viability of irradiated, treated cells. Cell viability was significantly lower in the post-irradiation sorafenib group versus the irradiation or pre-irradiation sorafenib group. Mean values were compared by using ANOVA. Mean $\pm S D(n=3)$. ${ }^{*}<0.05$ vs. Radiation group. 
fraction of SMMC-7221 and BEL-7402 cells: for example, sorafenib increased survival of irradiated (4 Gy) SMMC-7221 to $0.21 \pm 0.04$ and irradiated (4 Gy) BEL072 to $0.40 \pm 0.03$ (Figure 2A and 2B; Table 1) $(P<0.05$ in both). These data suggested that sorafenib given prior to irradiation rendered hepatocellular carcinoma cells more radio resistant. By contrast, post-irradiation sorafenib added $24 \mathrm{hr}$ post irradiation (4 Gy) decreased the surviving fraction of SMMC-7221 to $0.11 \pm 0.01$, and that of BEL-7402 cells to $0.21 \pm 0.03$ (Figure 2C and 2D, respectively; Table 1$) \quad(P<0.05$ for both). These data indicated that sorafenib given $24 \mathrm{~h}$ post irradiation increased the radio sensitivity of hepatocellular carcinoma cells. The above findings altogether suggested that sorafenib exerted a schedule-dependent effect on the sensitivity of hepatocellular carcinoma cells to radiation.
Pre-radiation sorafenib increased ability of irradiated hepatocellular carcinoma cells to subsequently repair DNA damage in vitro

Initially, we hypothesized that pre-radiation sorafenib increased the sensitivity of irradiated hepatocellular carcinoma cells to the formation of DNA double-strand breaks (DSBs). We monitored the formation of DSBs in SMMC-7721 and BEL-7402 cells by examining $\gamma$-H2AX induced foci by immunofluorescence. Hepatocellular carcinoma cells were treated with sorafenib for $30 \mathrm{~min}$ prior to radiation (6 Gy). Our immunofluorescence assays showed that $94.6 \pm 3.5 \%$ of irradiated SMMC7721 and $64.7 \pm 2.9 \%$ of irradiated BEL-7402 cells were positive for $\gamma$-H2AX. Similarly, $93.9 \pm 4.7 \%$ and $62.7 \pm$ $4.0 \%$ of SMMC-7721 and BEL-7402 cells that received both radiation and sorafenib were positive for $\gamma-\mathrm{H} 2 \mathrm{AX}$

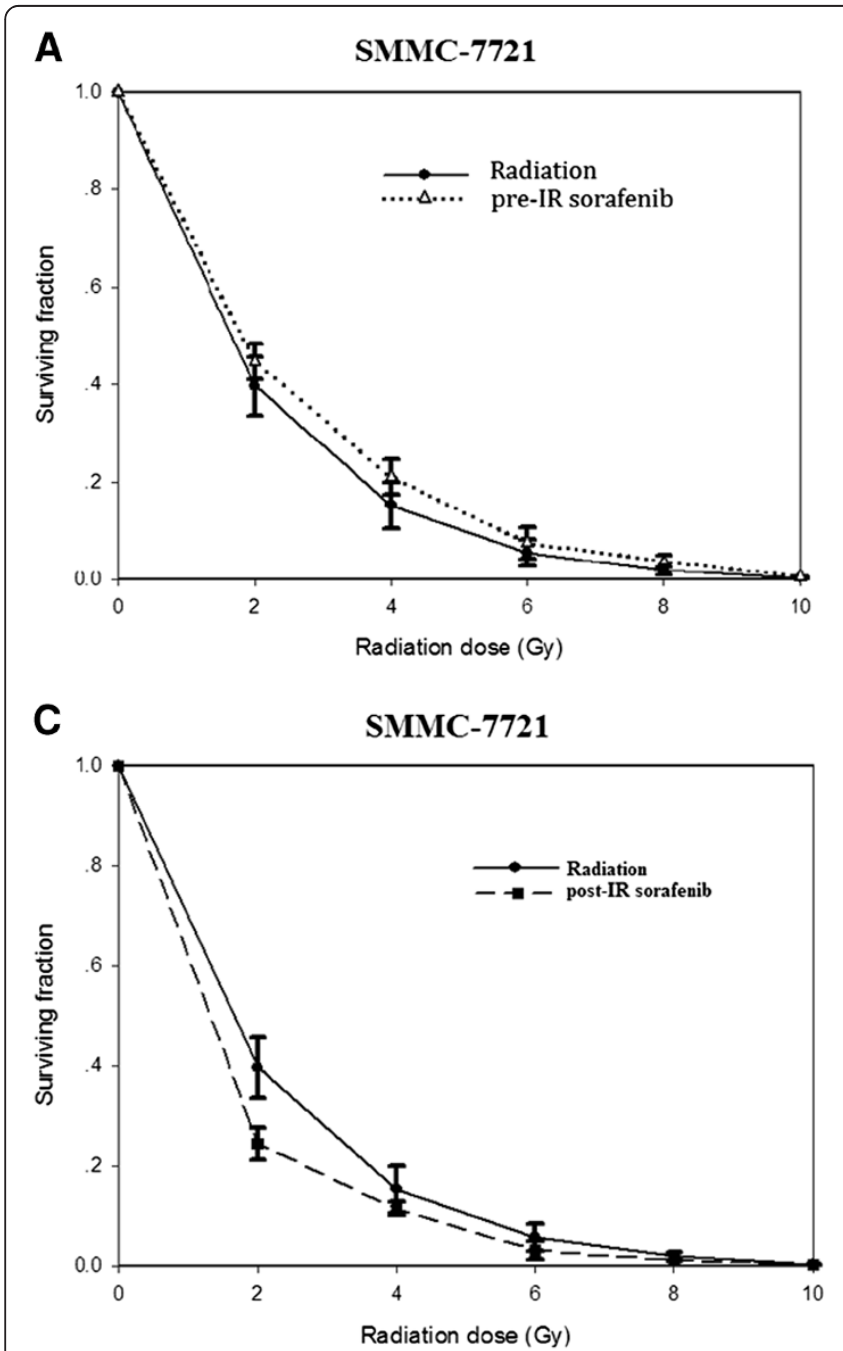

B

B BEL-7402

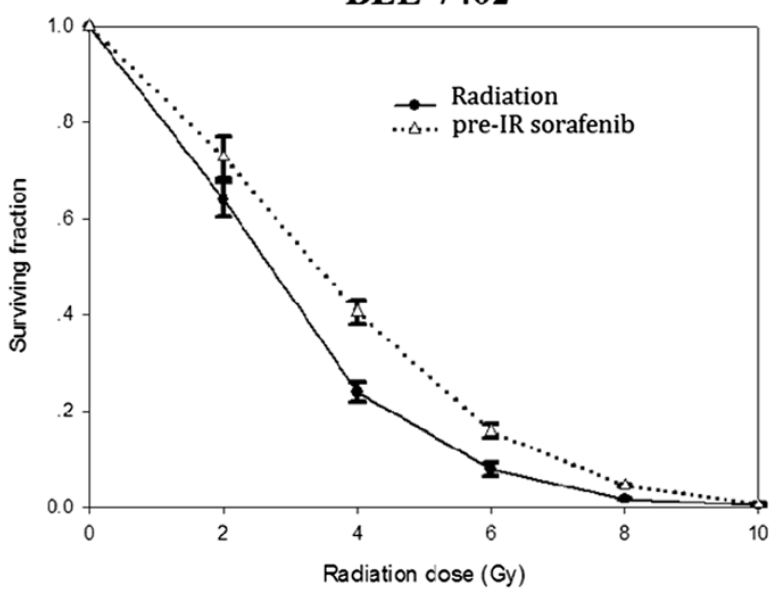

D

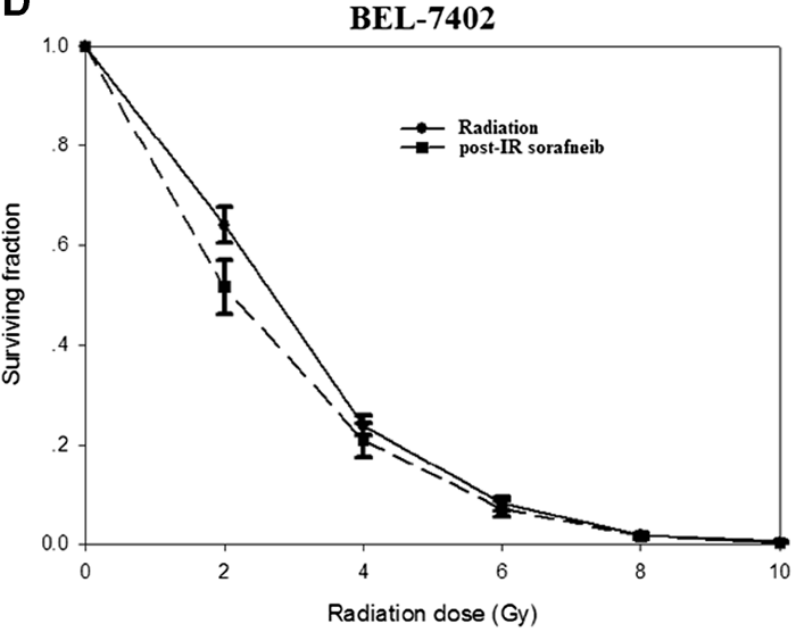

Figure 2 Clonogenic survival of human hepatocellular carcinoma cells SMMC-7721 (A, C) and BEL-7402 (B, D) after irradiation with or without sorafenib. A, B Sorafenib (15 mM) was added $30 \mathrm{~min}$ prior to irradiation of cells (pre-IR sorafenib). C, D. Cells were irradiated (0-10 Gy) and sorafenib was added $24 \mathrm{~h}$ post irradiation (post-IR sorafenib). Survival fraction (SF) was calculated by using the mean plating efficiency (PE) of untreated cells as the denominator to illustrate independent cytotoxic effects of sorafenib; linear quadratic (LQ) equation was fitted to data. 


\section{Table 1 Mean values for and (and standard errors of the means) calculated by fitting the LQ equation to clonogenic survival}

\begin{tabular}{|c|c|c|c|c|}
\hline & $a$ & SEM & $\beta$ & SEM \\
\hline \multicolumn{5}{|l|}{ SMMC-7721 } \\
\hline IR & -1.271 & 0.028 & 0.866 & 0.020 \\
\hline $\mathrm{IR} \pm$ Sorafenib pre & -1.295 & 0.021 & 0.850 & 0.011 \\
\hline \multicolumn{5}{|l|}{ (Sorafenib delivered 30 min pre-IR) } \\
\hline $\mathrm{IR} \pm$ Sorafenib post & -1.145 & 0.035 & 0.927 & 0.017 \\
\hline \multicolumn{5}{|l|}{ (Sorafenib delivered $24 \mathrm{~h}$ post-IR) } \\
\hline \multicolumn{5}{|l|}{ BEL-7402 } \\
\hline IR & -1.384 & 0.013 & 0.804 & 0.007 \\
\hline$\underline{I R} \pm$ Sorafenib pre & -1.412 & 0.014 & 0.785 & 0.008 \\
\hline \multicolumn{5}{|l|}{ (Sorafenib delivered 30 min pre-IR) } \\
\hline $\mathrm{IR} \pm$ Sorafenib post & -1.331 & 0.026 & 0.831 & 0.136 \\
\hline (Sorafenib delivered $24 \mathrm{~h}$ post-IR) & & & & \\
\hline
\end{tabular}

Abbreviations: LQ: linear quadratic; IR: irradiation; SEM: standard error of the mean.

(Figure 3A to 3C) $(P>0.05$ in both). These data indicated that pre-irradiation sorafenib did not promote radiation-induced DSBs. We hypothesized that sorafenib may promote the repair of radiation-induced DNA damages. Thus, we compared the percentage of sorafenib-treated (30 min prior), irradiated (6 Gy) cells for $\gamma$-H2AX immunofluorescence to radiation treated cells. At $6 \mathrm{~h}$ post irradiation, irradiated SMMC-7721 cells had significantly higher $\gamma$-H2AX immunofluorescence $(59.9 \pm 2.4 \%)$ than pre-radiation sorafenib-treated, irradiated SMMC-7721 cells $(23.8 \pm 2.9 \%) \quad(\mathrm{P}<0.001)$. Similarly, pre-radiation sorafenib-treated, irradiated BEL-7402 cells had fewer $\gamma$-H2AX positive cells $(25.0 \pm$ $3.0 \%)$ than only irradiated BEL-7402 cells $(46.4 \pm 3.8 \%)$ $(\mathrm{P}<0.001)$ (Figure $3 \mathrm{~A}$ to $3 \mathrm{C})$.

\section{Pre-irradiation sorafenib delayed the activation of radiation-induced G2/M checkpoint in hepatocellular carcinoma cells}

Radiation-induced DNA damages lead to the activation of G2/M checkpoint. We investigated whether sorafenib given prior to or following irradiation of hepatocellular carcinoma cells impacted radiation-induced changes in distribution of cell cycle stages. Sorafenib alone induced no apparent changes in cell cycle distribution of either SMMC-7721and BEL-7402cells while, as expected, irradiation (6 Gy) caused a significant increase in the percentage of both SMMC-7721 and BEL-7402cells in $\mathrm{G} 2 / \mathrm{M}$ at 12 to $16 \mathrm{~h}$ post radiation (Figure 4). Preirradiation sorafenib also induced an accumulation of the hepatocellular carcinoma cells in G2/M, but this increase in the percentage of cells in G2/M was significantly delayed to 24 to $30 \mathrm{~h}$ post irradiation in SMMC7721 cells and BEL-7402 cells.
Sorafenib induced apoptosis of hepatocellular carcinoma cells in vitro

Sorafenib reduced proliferation of hepatocellular carcinoma cells in CCK8 assays with an IC50 of $25.09 \pm$ $4.49 \mu \mathrm{M}$ for SMMC-7721 cells and an IC50 of $28.90 \pm$ $1.07 \mu \mathrm{M}$ for BEL-7402 cells. To examine whether sorafenib induced apoptosis of the hepatocellular carcinoma cells, SMMC-7721and BEL-7402 cells were treated with sorafenib alone. After $24 \mathrm{~h}$, cells were stained with annexin $\mathrm{V}$ and propidium iodide to assess percentage of cells undergoing apoptosis. The apoptotic rate in untreated SMMC-7721 $(3.4 \pm 2.2 \%)$ significantly increased more than 4 fold to $18.3 \pm 2.9 \%(\mathrm{P}<0.001)$ in sorafenibtreated SMMC-7721 (Figure 5A). Sorafenib treatment also increased the apoptotic rate in BEL-7402 cells from $7.2 \pm 1.5 \%$ to $16.1 \pm 2.7 \%(\mathrm{P}<0.001)$ (Figure $5 \mathrm{~B})$. Radiation did not induce apparent apoptosis of the hepatocellular carcinoma cells SMMC-7721 (6.1 $\pm 1.0 \%)$ compared to controls $(4.5 \pm 2.3 \%)$ or the BEL-7402 cells $(8.2 \pm 2.1 \%, \mathrm{vs} 8.0 \pm 1.5 \%$ in controls). Interestingly, preirradiation sorafenib significantly increased the number of apoptotic cells (SMMC-7721, $18.3 \pm 2.0 \%, P<0.05$ vs. controls; BEL-7402, $17.0 \pm 2.4 \%, P<0.05$ vs. controls). Post-irradiation sorafenib treatment significantly increased the number of apoptotic cells (SMMC-7721, $15.9 \pm 1.8 \%, P<0.05$ vs. controls; BEL-7402, $14.2 \pm 2.5 \%$, $P<0.05$ vs. controls) but to a lesser extent than sorafenib treatment alone. Both pre-irradiation sorafenib and post-irradiation sorafenib induced apoptosis in the hepatocellular cells to a similar extent.

\section{Discussion}

Here, we showed that sorafenib modulated the response of hepatocellular carcinoma cells to radiation and, furthermore, this modulation was schedule-dependent. We found that post-irradiation sorafenib radio sensitized hepatocellular carcinoma cells by inhibiting the clonogenic growth of the hepatocellular carcinoma cells. In contrast, pre-irradiation sorafenib did not radio sensitize these hepatocellular carcinoma cells in vitro, which is similar to the findings in colorectal carcinoma $[10,11]$. Wilson and colleagues [11] investigated the effect of different schedules of sorafenib against irradiated colorectal cancer and pancreatic cancer cells. Only sorafenib given $24 \mathrm{~h}$ post irradiation, but not concurrently, potentiated the inhibition of clonogenic growth of irradiated cancer cells [11]. In addition, Plastaras et al. [10] found that radiation alone or sorafenib treatment prior to radiation did not significantly reduce the growth of mouse colorectal cancer xenografts. These above findings suggest that sorafenib exerts a schedule-dependent effect on colorectal carcinoma cells with post-irradiation sorafenib being the most effective in inhibiting tumor growth in mouse models. 


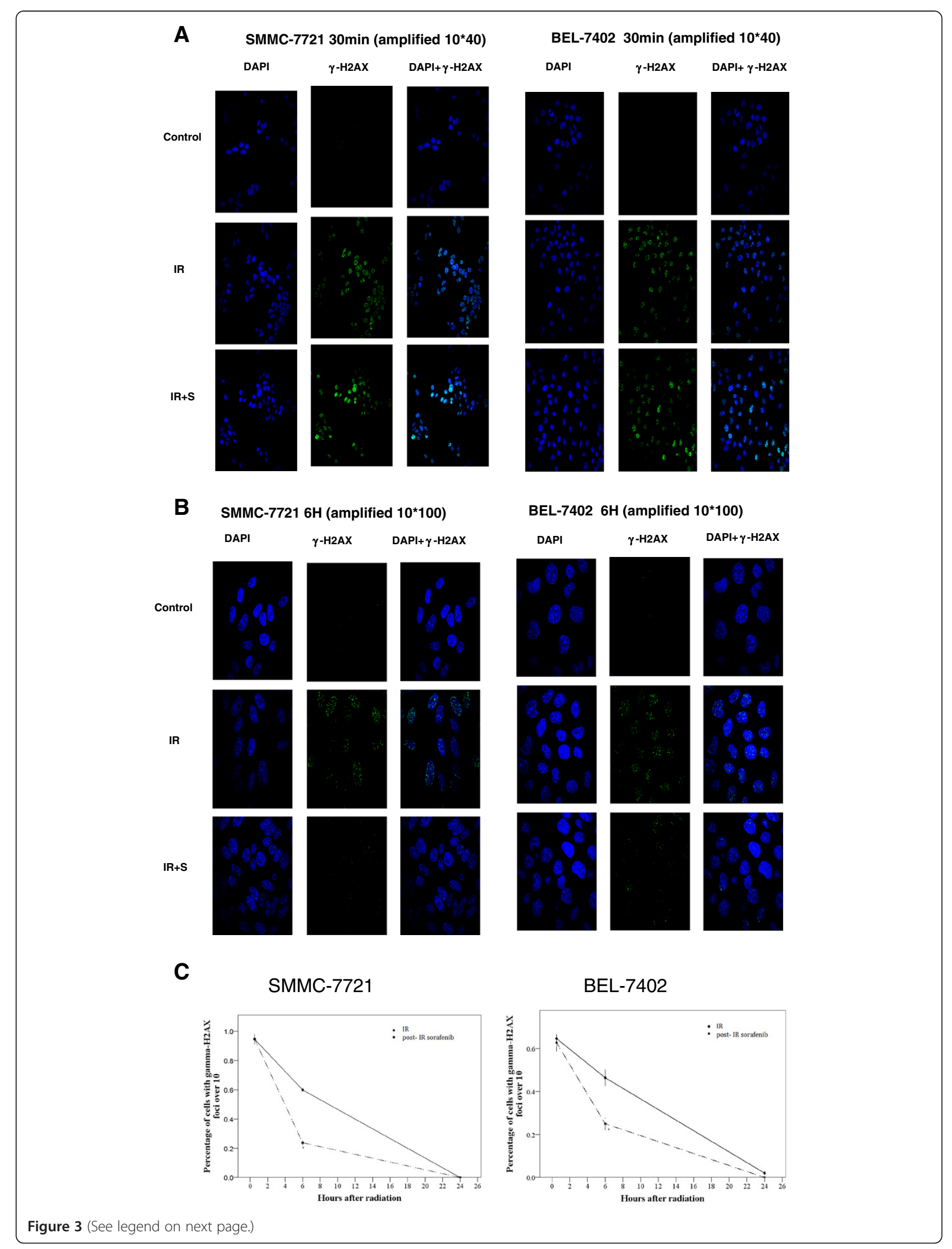


(See figure on previous page.)

Figure 3 Effect of sorafenib on DNA damage of irradiated SMMC-7721 and BEL-7402 cells. Treated cells were stained with DAPI and anti- $\gamma$-H2AX antibody. A. Sorafenib was added to SMMC-7721 and BEL-7402 cells 30 min prior to their irradiation (6 Gy). B. Post-irradiation sorafenib treated cells were incubated for $6 \mathrm{~h}$ before staining. C. Percentage of cells with $\geq 10 \mathrm{Y}-\mathrm{H} 2 \mathrm{AX}$ foci. Comparisons of mean values were performed using the independent two sample $t$ test. Mean $\pm S D(n=3) .{ }^{*} P<0.05$ vs. the radiation group.

Clonogenic cell survival after DNA damage is regulated by two main cell death pathways: interphase apoptotic cell death pathway and mitotic catastrophe $[16,18]$. Radiation induces mitotic catastrophe $[18,19]$ which occurs in cells with unrepaired DNA damage that prematurely enter mitosis. Mitotic catastrophe is regulated by at least p53, survivin, cell-cycle checkpoint proteins, and cell-cycle specific kinases [20]. To assess whether the schedule-dependent effect of sorafenib on irradiated cells is associated with mitotic catastrophe, we monitored DNA damage in irradiated hepatocellular carcinoma cells by examining $\gamma$-H2AX

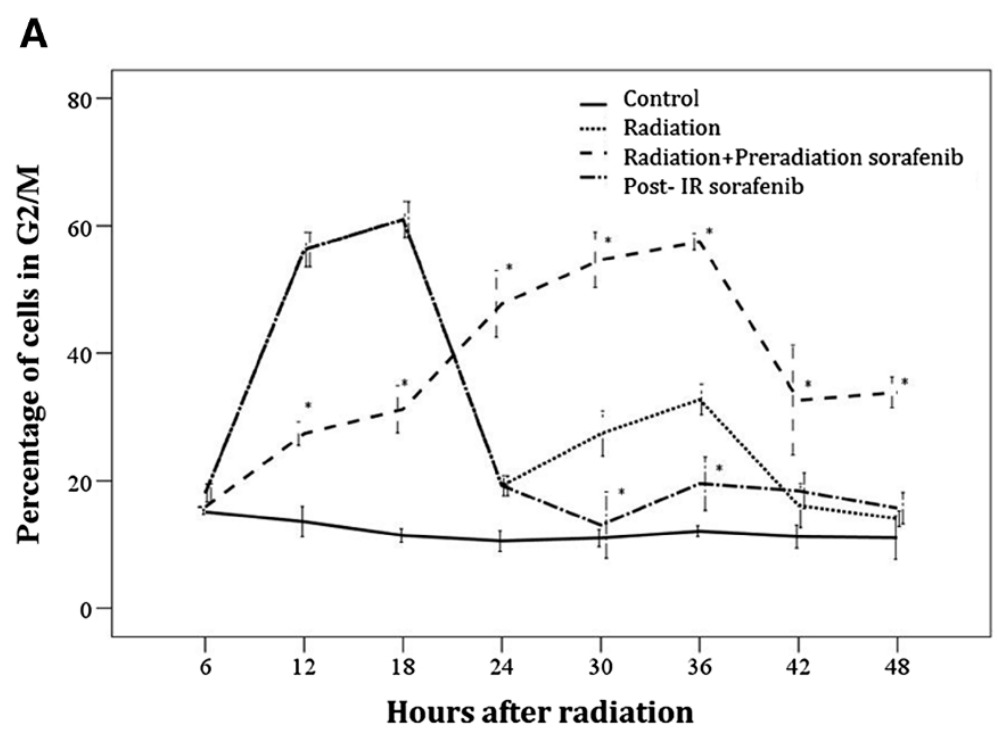

B

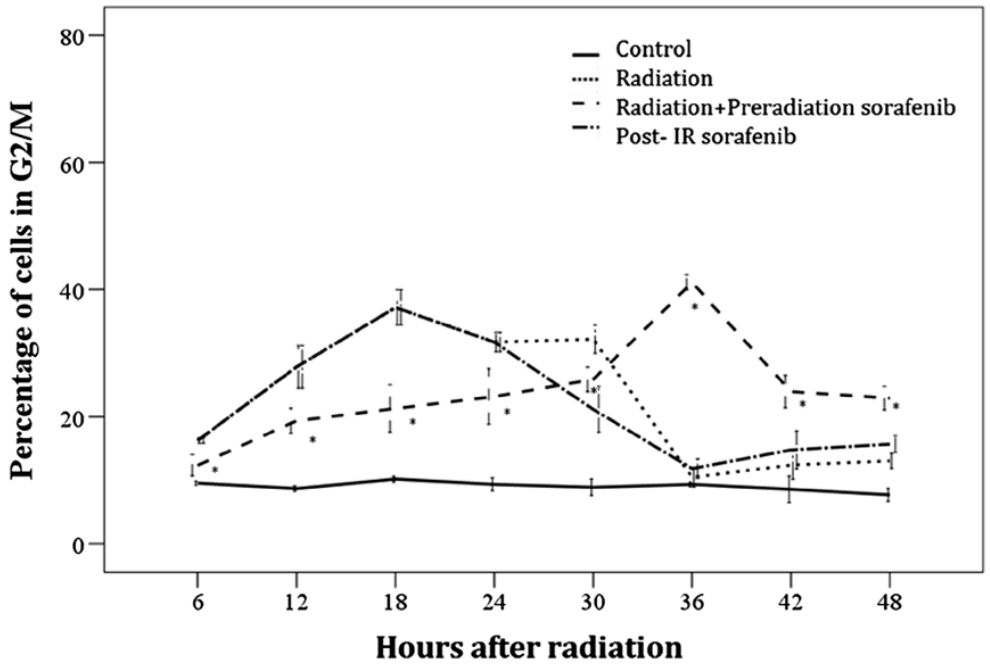

Figure 4 Effects of sorafenib treatments on cell cycle distribution of SMMC-7721 and BEL-7402. Cells were treated with 6 Gy radiation (radiation), $15 \mu \mathrm{M}$ sorafenib 30 min before 6 Gy radiation (radiation + preradiation sorafenib), or radiation followed 24 hrs later with $15 \mu \mathrm{M}$ sorafenib (radiation + post radiation sorafenib), or untreated (control). Fixed cells were stained with propidium iodide and analyzed for DNA content by flow cytometry. A. SMMC-7721. B. BEL-7402. Percentage of hepatocellular carcinoma cells in G2 phase. Comparisons of mean values were performed by using ANOVA. Mean $\pm S D(n=3) .{ }^{*} P<0.05$ vs. the radiation group. 


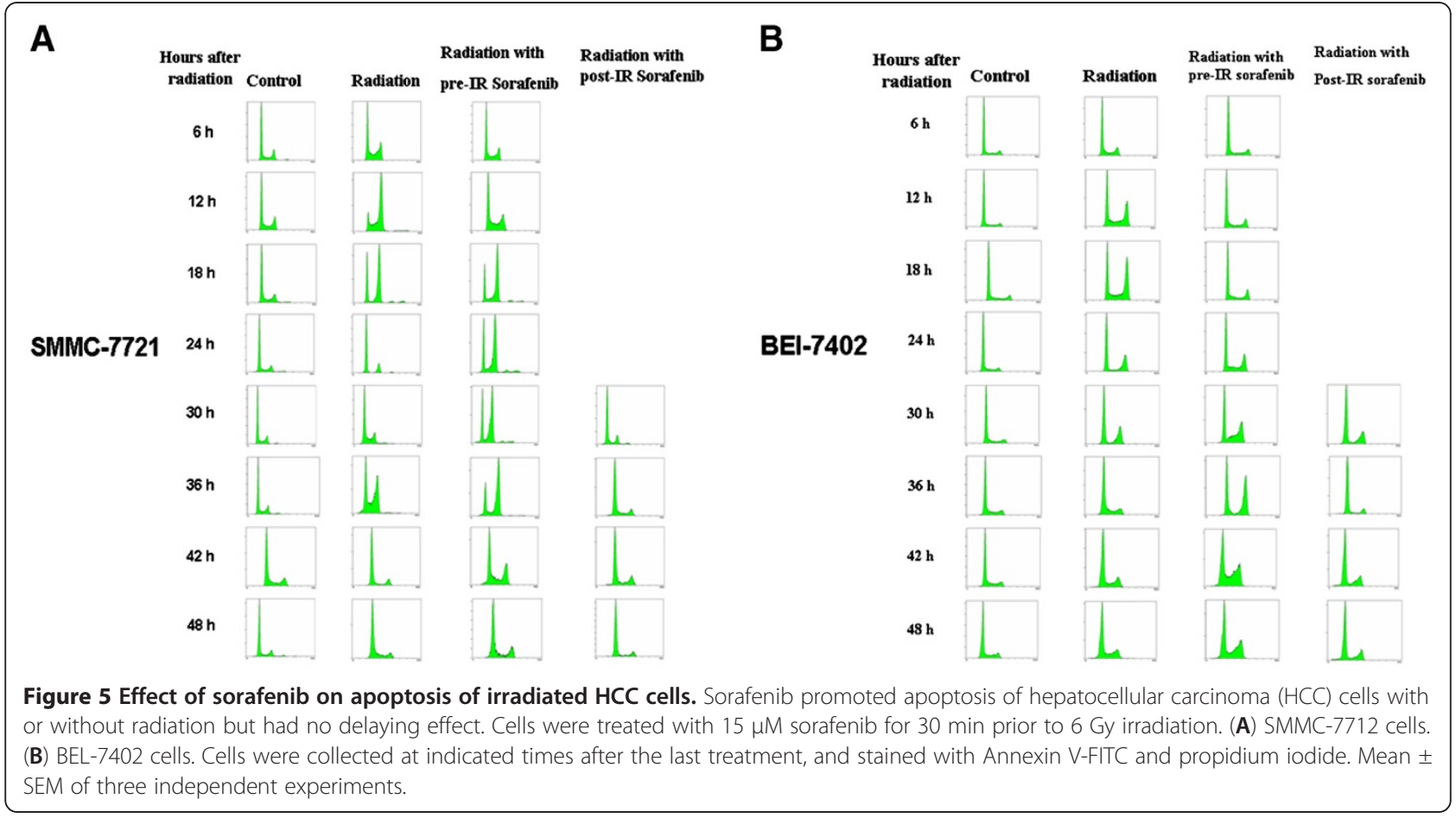

foci with immunofluorescence microscopy. Pre-radiation sorafenib treatment had no effect on the formation of DNA DSBs, but promoted repair of DNA damages, which could lessen the chance of mitotic catastrophe. DNA damage had been almost completely repaired in the irradiated hepatocellular carcinoma cells since less than $5 \%$ of the irradiated cells contained significant DNA damage $(\geq 10$ $\gamma$-H2AX foci). We speculate that post-irradiation sorafenib did not increase repair of DNA damages in HCC. The distinct effects on DNA repair by the two schedules of sorafenib may partially explain the enhanced $\mathrm{HCC}$ viability with pre-irradiation sorafenib compared to the lower cell viability in irradiated $\mathrm{HCC}$ samples treated with sorafenib 24 post radiation.

The activation of cell cycle checkpoints plays a significant role in the DNA damage response. It prevents damaged cells from entering the next phase of the cell cycle. Prolonged G2 arrest appears to contribute to the ability of the cell to survive radiation [21,22]. As expected, we found that irradiation induced the activation of the G2/M checkpoint in hepatocellular carcinoma cells at $16 \mathrm{~h}$ post irradiation. Additionally, we observed that pre-irradiation sorafenib delayed the onset of the G2/M checkpoint, which could allow more time for the irradiated hepatocellular carcinoma cells to repair DNA damages. Our clonogenic assays showed that sorafenib given prior to irradiation rendered hepatocellular carcinoma cells more radio resistant, which could be due to the delayed onset of the G2/M checkpoint, allowing the irradiated cells more time to repair DNA damages. As expected, HCC cells treated with postirradiation sorafenib had no effect on the G2/M peak at 16 hrs post radiation.

As the current study was carried out in vitro, we did not examine the anti-angiogenic effect of sorafenib on radio sensitivity in hepatocellular carcinoma cells. We found that sorafenib exerts a schedule-dependent effect on $\mathrm{HCC}$ radio sensitivity, which could be of significance for the treatment of hepatocellular carcinoma patients with sorafenib in combination with adjuvant radiotherapy. Our findings suggest that the efficacy of sorafenibbased therapy in combination with radiotherapy may depend on the timing of sorafenib administration relative to that of radiotherapy. On the basis of our in vitro studies, we speculate that post-irradiation sorafenib could be more effective in potentiating tumor inhibitory effect of radiotherapy. Further studies are needed to confirm this schedule-dependent effect of sorafenib in animal models bearing human hepatocellular carcinoma xenografts and in clinical studies.

\section{Conclusions}

Sorafenib combined with irradiation exerted a scheduledependent effect in HCC cells in vitro.Sorafenib given $30 \mathrm{~min}$ prior to irradiation reduced the anti-proliferative effects of irradiation against HCC whereas sorafenib given $24 \mathrm{hr}$ after irradiation increased the anti-tumor effects against HCC. These results have significant implications for the combined use of sorafenib and radiotherapy against $\mathrm{HCC}$ in the clinic. 


\section{Abbreviations}

DSB: Double-strand breaks; HCC: Hepatocellular carcinoma; MTT: 3-(4,5dimethylthiazol-2-yl)-5(3-carboxymethoxyphenyl)-2(4-sulfophenyl)-2 Hterazolium; OD: Optical density; PBS: Phosphate buffered saline; SD: Standard deviation; SEM: Standard error of the mean.

\section{Competing interests}

None of the authors has any conflict of interest to report.

\section{Authors' contributions}

QL and YH carried out the molecular genetic studies, participated in the sequence alignment and drafted the manuscript. MX carried out the immunoassays. LH participated in the sequence alignment. LZ participated in the design of the study and performed the statistical analysis. ML conceived of the study, participated in its design and coordination, and helped to draft the manuscript. All authors read and approved the final manuscript.

\section{Acknowledgments}

The authors also thank Katherine L. Molnar-Kimber, Ph.D. and Gere Biotech who provided medical editing services that were funded by the authors.

Received: 18 May 2012 Accepted: 23 September 2012

Published: 22 October 2012

\section{References}

1. Parkin DM: Global cancer statistics in the year 2000. Lancet Oncol 2001, 2(9):533-543.

2. Hung H: Treatment modalities for hepatocellular carcinoma. Curr Cancer Drug Targets 2005, 5(2):131-138.

3. Ben-Josef E, Normolle D, Ensminger WD, Walker S, Tatro D, Ten Haken RK, Knol J, Dawson LA, Pan C, Lawrence TS: Phase II trial of high-dose conformal radiation therapy with concurrent hepatic artery floxuridine for unresectable intrahepatic malignancies. J Clin Oncol 2005, 23(34):8739-8747.

4. Seong J, Lee IJ, Shim SJ, Lim Do H, Kim TH, Kim JH, Jang HS, Kim MS, Chie EK, Nam TK, et al: A multicenter retrospective cohort study of practice patterns and clinical outcome on radiotherapy for hepatocellular carcinoma in Korea. Liver Int 2009, 29(2):147-152.

5. Park W, Lim DH, Paik SW, Koh KC, Choi MS, Park CK, Yoo BC, Lee JE, Kang MK, Park YJ, et al: Local radiotherapy for patients with unresectable hepatocellular carcinoma. Int I Radiat Oncol Biol Phys 2005, 61(4):1143-1150.

6. Strumberg D: Preclinical and clinical development of the oral multikinase inhibitor sorafenib in cancer treatment. Drugs Today (Barc) 2005, 41(12):773-784.

7. Cheng AL, Kang YK, Chen Z, Tsao CJ, Qin S, Kim JS, Luo R, Feng J, Ye S, Yang TS, et al: Efficacy and safety of sorafenib in patients in the AsiaPacific region with advanced hepatocellular carcinoma: a phase III randomised, double-blind, placebo-controlled trial. Lancet Oncol 2009, 10(1):25-34

8. Llovet JM, Ricci S, Mazzaferro V, Hilgard P, Gane E, Blanc JF, de Oliveira AC, Santoro A, Raoul JL, Forner A, et al: Sorafenib in advanced hepatocellular carcinoma. N Engl J Med 2008, 359(4):378-390.

9. Liu L, Cao Y, Chen C, Zhang X, McNabola A, Wilkie D, Wilhelm S, Lynch M, Carter C: Sorafenib blocks the RAF/MEK/ERK pathway, inhibits tumor angiogenesis, and induces tumor cell apoptosis in hepatocellular carcinoma model PLC/PRF/5. Cancer Res 2006, 66(24):11851-11858.

10. Plastaras JP, Kim SH, Liu YY, Dicker DT, Dorsey JF, McDonough J, Cerniglia G, Rajendran RR, Gupta A, Rustgi AK, et al: Cell cycle dependent and schedule-dependent antitumor effects of sorafenib combined with radiation. Cancer Res 2007, 67(19):9443-9454.

11. Suen AW, Galoforo S, Marples B, McGonagle M, Downing L, Martinez AA, Robertson JM, Wilson GD: Sorafenib and radiation: a promising combination in colorectal cancer. Int J Radiat Oncol Biol Phys 2010, 78(1):213-220

12. Kasibhatla M, Steinberg P, Meyer J, Ernstoff MS, George DJ: Radiation therapy and sorafenib: clinical data and rationale for the combination in metastatic renal cell carcinoma. Clin Genitourin Cancer 2007, 5(4):291-294.

13. Hsieh CH, Jeng KS, Lin CC, Chen CK, Liu CY, Lin CP, Tai HC, Wang CH, Shueng PW, Chen YJ: Combination of sorafenib and intensity modulated radiotherapy for unresectable hepatocellular carcinoma. Clin Drug Investig 2009, 29(1):65-71.

14. Zhang Y, Chen LH, Wang L, Wang HM, Zhang YW, Shi YS: Radiationinducible PTEN expression radiosensitises hepatocellular carcinoma cells. Int J Radiat Biol 2010, 86(11):964-974.

15. Liang Y, Zhong Z, Huang Y, Deng W, Cao J, Tsao G, Liu Q, Pei D, Kang T, Zeng YX: Stem-like cancer cells are inducible by increasing genomic instability in cancer cells. J Biol Chem 2010, 285(7):4931-4940.

16. Cao JX, Cui YX, Long ZJ, Dai ZM, Lin JY, Liang Y, Zheng FM, Zeng YX, Liu Q: Pluripotency-associated genes in human nasopharyngeal carcinoma CNE-2 cells are reactivated by a unique epigenetic submicroenvironment. BMC Cancer 2010, 10:68.

17. Deng R, Tang J, Xia LP, Li DD, Zhou WJ, Wang LL, Feng GK, Zeng YX, Gao YH, Zhu XF: ExcisaninA, a diterpenoid compound purified from Isodon MacrocalyxinD, induces tumor cells apoptosis and suppresses tumor growth through inhibition of PKB/AKT kinase activity and blockade of its signal pathway. Mol Cancer Ther 2009, 8(4):873-882.

18. Eriksson D, Stigbrand T: Radiation-induced cell death mechanisms. Tumour Biol 2010, 31(4):363-372.

19. Chan TA, Hermeking H, Lengauer C, Kinzler KW, Vogelstein B: 14-3-3Sigma is required to prevent mitotic catastrophe after DNA damage. Nature 1999, 401(6753):616-620.

20. Castedo M, Perfettini JL, Roumier T, Andreau K, Medema R, Kroemer G: Cell death by mitotic catastrophe: a molecular definition. Oncogene 2004, 23(16):2825-2837.

21. Lukas J, Lukas C, Bartek J: Mammalian cell cycle checkpoints: signalling pathways and their organization in space and time. DNA Repair (Amst) 2004, 3(8-9):997-1007.

22. Cann KL, Hicks GG: Regulation of the cellular DNA double-strand break response. Biochem Cell Biol 2007, 85(6):663-674.

doi:10.1186/1471-2407-12-485

Cite this article as: Li et al: Sorafenib modulates the radio sensitivity of hepatocellular carcinoma cells in vitro in a schedule-dependent manner. BMC Cancer 2012 12:485.

\section{Submit your next manuscript to BioMed Central and take full advantage of:}

- Convenient online submission

- Thorough peer review

- No space constraints or color figure charges

- Immediate publication on acceptance

- Inclusion in PubMed, CAS, Scopus and Google Scholar

- Research which is freely available for redistribution 